\title{
KARAKTERISTIK SPONDILITIS TUBERCULOSIS DI RSUP NTB JANUARI - DESEMBER 2012
}

\author{
E. Hagni Wardoyo ${ }^{1}$, Muthia Cenderadewi ${ }^{2}$, Hadian Rahman ${ }^{3}$, Novia Andansari Putri $^{4}$ Dyah Purnaning ${ }^{5}$ \\ ${ }^{1}$ Bagian Mikrobiologi, ${ }^{2}$ Bagian Parasitologi, ${ }^{3}$ Bagian Bedah, ${ }^{4}$ Bagian Radiologi, ${ }^{4}$ Subbagian \\ Ortopedi Fakultas Kedokteran Universitas Mataram
}

\begin{abstract}
Abstrak : Penelitian ini bertujuan untuk memperoleh karakteristik spondilitis tuberculosis di RSUP NTB selama tahun 2012. Penelitian ini dilakukan dengan desain penelitian observasional yang diambil dari data rekam medik dengan klasifikasi diagnosis menurut ICD 10 A18.10 (tuberculosis of the spine). Sepanjang tahun 2012 terdapat 19 kasus spondilitis tuberculosis (8 perempuan, 11 laki-laki). Rentang usia dimulai dari usia 9-60 tahun. Seluruh subyek memiliki penyakit/gejala penyerta: TB paru (4/19), anemia (2/19), gizi buruk (3/19), sepsis (1/19), meningoensefalitis (1/19), fraktur kompresi vertebra (8/19). Tindakan operasi laminektomi dilakukan pada 15 subyek dan dilanjutkan pemberian obat anti tuberculosis. Kasus didominasi oleh laki-laki. Seluruh kasus spondylitis TB di NTB memiliki penyakit penyerta dengan kasus tertinggi fraktur kompresi vertebra. Sebagian besar kasus (15/19) memerlukan tindakan laminektomi.
\end{abstract}

Kata Kunci: Spondilitis Tuberkulosis, NTB

\section{CHARACTERISTICS SPONDYLITIS TUBERCULOSIS IN GENERAL HOSPITAL CENTER NTB PERIODE JANUARY-DECEMBER 2012}

\begin{abstract}
The objective of the study is to describe clinical characteristic in West Nusa Tenggara Province Referral Hospital in 2012. Observational design was established using hospital's record with ICD 10 codes A18.10 (tuberculosis of the spine). During 2012 found 19 cases of spondylitis tuberculosis (8 female, 11 male). Age interval between 9-60 years old. The accompanying conditions are: lung TB (4/19), anemia (2/19), severe malnutrition (3/19), sepsis (1/19), meningoencephalitis (1/19), compression fracture of the vertebrae (8/19). Laminectomy was done to 15 subject and antituberculosis drugs. The majority cases are male, all cases having accompanying conditions with compression fracture of vertebrae as most frequent condition. Majority of cases are need laminectomy.
\end{abstract}

Keywords: spondylitis tuberculosis, West Nusa Tenggara province

Korespondensi : dr. E. Hagni Wardoyo, SpMK Bagian Mikrobiologi RSUP NTB

Email: wardoyo.eh@unram.ac.id

\section{PENDAHULUAN}

Spondilitis tuberkulosis (spondilitis TB) adalah penyakit infeksi yang disebabkan oleh kuman Mycobacterium tuberculosis yang mengenai tulang belakang, Spondilitis TB masih menjadi masalah kesehatan yang utama di Negara berkembang. Sekitar 1-2\% dari total kasus tuberculosis berhubungan dengan spondilitis $\mathrm{TB}^{1,2,3}$.

Spondilitis TB merupakan penyakit dengan morbiditas yang tinggi antara lain kerusakan vertebra yang mengakibatkan deformitas serta deficit neurologis yang berat yang dapat timbul secara cepat ataupun lambat. Morbiditas spondilitis TB yang tinggi ini menjadi alasan peneliti untuk melakukan studi terhadap karakteristik spondilitis TB di RSUP NTB yang merupakan rumah sakit rujukan utama di Propinsi NTB.

Berdasarkan laporan WHO, kasus baru TB di dunia lebih dari 8 juta per tahun. Diperkirakan 20-33\% dari penduduk dunia terinfeksi oleh Mycobacterium tuberculosis ${ }^{4}$.

Paru merupakan port d'entree lebih dari $98 \%$ kasus infeksi TB. Kuman dapat menyebar melalui limfogen ataupun hematogen. Organ yang dituju adalah organ yang mempunyai vaskularisasi baik, misalnya otak, tulang, ginjal, dan paru sendiri, terutama apeks paru atau lobus atas paru ${ }^{4}$.

Spondilitis TB dapat mengakibatkan deformitas serta deficit neurologis yang dapat timbul secara cepat ataupun lambat. Defisit neurologis yang timbul secara cepat dapat berupa paralisis akibat abses sedangkan secara lambat 
oleh karena perkembangan dari kiposis, kolaps vertebra dengan retro pulsi dari tulang dan debris. Gejala lain yang dapat timbul antara lain demam tanpa sebab yang jelas, nyeri punggung, berat badan yang menurun, pembesaran limfonodi, dan gejala khas TB lain.

Pemeriksaan rutin yang biasadilakukan untuk menentukan adanya infeksi Mycobacterium tuberculosis adalah dengan menggunakan uji tuberkulin(tes Mantoux. LED yang meningkat dengan basil $>100 \mathrm{~mm} / \mathrm{jam}$ juga dapat mengarahkan pada diagnosis tuberculosis. Pada fotopolos vertebrae, dapat ditemukan osteoporosis, osteolitik dan destruksi korpus vertebrae, disertai penyempitan diskus intervertebralis yang berada di antara korpus tersebut dan mungkin dapat ditemukan adanya massa abses paravertebral.

Diagnosis spondilitis TB dapat ditegakkan dengan riwayat kontak dekat dengan pasien TB, gejala klinis dan pemeriksaan neurologi. Pemeriksaan laboratorium dengan ditemukannya basil Mycobacterium tuberculosis akan memberikan diagnosis pasti, sedangkan metode pencitraan modern sepertix-ray, CT scan, dan MRI akan sangat membantu menegakkan diagnosis spondilitis TB.

Penatalaksanaan spondilitis TB dapat melalui medikamentosa (non operatif) ataupun operatif. (Mood et al, 2006). Pengobatan Potts paraplegi paling penting adalah imobilisasi dan artrodesis posterior awal ${ }^{4}$.

\section{METODE PENELITIAN}

Penelitian ini merupakan penelitian observasional dengan pendekatan deskriptif retrospektif. Penelitian ini dilaksanakan selama 4 bulan, yaitu bulan Mei sampai dengan Agustus 2013 di bagian rekam medik RSUP NTB.

Populasi penelitian ini adalah semua pasien spondilitis TB yang dirawat di RSUP NTB dari Januari 2012-Desember 2012.

\section{HASIL DAN PEMBAHASAN PENELITIAN}

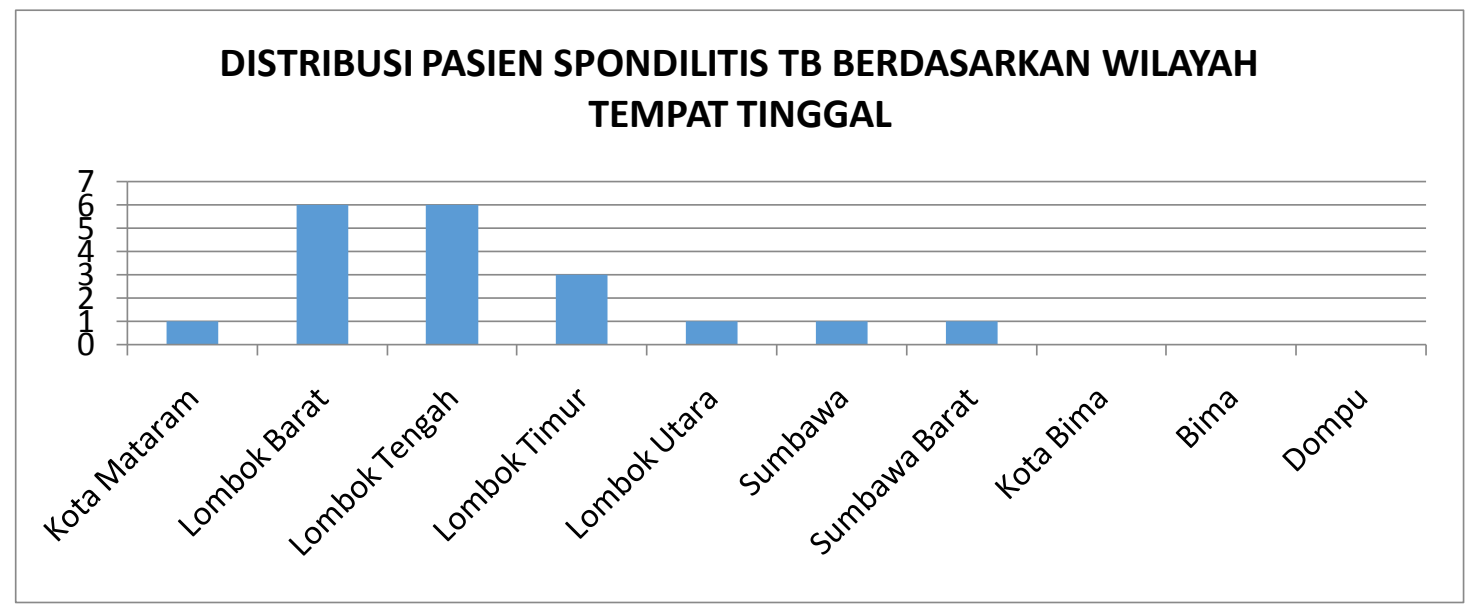

Gambar 1. Distribusi demografik tempat tinggal pasien

Pasien spondilitis TB yang dirawat di RSUP NTB pada tahun 2012, terbanyak berasal dari Kab. Lombok Barat dan Kab. Lombok Tengah (6), disusul Kab. Lombok Timur (3), Kota Mataram (1), Kab. Lombok Utara (1), Kab. Sumbawa (1), dan Kab. Sumbawa Barat (1). Jika dihubungkan dengan data TB paru per kabupaten di
NTB maka hasil ini menunjukkan ketidaksesuaian dengan kasus TB paru, dimana jumlah kasus TB paru tertinggi terdapat di Kab Lombok Timur, disusul kota Bima, Kab. Lombok Tengah, Kab Bima, Kab Sumbawa Barat, Kab. Dompu, Kab. Lombok Barat, Kab. Sumbawa, Kab. Lombok Utara dan Kota Mataram ${ }^{6}$. 
Tabel 1. Karakteristik pasien spondilitis TB di RSUP NTB

\begin{tabular}{|c|c|c|c|}
\hline No & Karakteristik & $\mathbf{n}$ & Keterangan \\
\hline 1 & Usia & Median $26(9-60)$ & \\
\hline \multirow[t]{3}{*}{2} & Jenis Kelamin & & \\
\hline & Perempuan & $8(42,10 \%)$ & \\
\hline & Laki-laki & $11(57,90 \%)$ & \\
\hline \multirow[t]{3}{*}{3} & Letak gibus & & \\
\hline & Thorakal & $5(26,3 \%)$ & \\
\hline & Lumbal & $14(73,7 \%)$ & \\
\hline \multirow[t]{3}{*}{4} & Keluhan neurologis & & \\
\hline & paraparese inferior & $4(21 \%)$ & \\
\hline & hemiparese & $1(5,3 \%)$ & \\
\hline \multirow[t]{7}{*}{5} & Penyakit/gejala penyerta & & \\
\hline & Lesi primer (TB paru) & $4(21 \%)$ & \\
\hline & Anemia & $2(10,5 \%)$ & \\
\hline & GiziBuruk & $3(15,8 \%)$ & \\
\hline & Sepsis & $1(5,3 \%)$ & \\
\hline & Meningo ensepalitis & $1(5,3 \%)$ & \\
\hline & Fraktur Kompresi pada Vertebra & $8(42,1 \%)$ & \\
\hline \multirow[t]{8}{*}{6} & Pemeriksaan penunjang & & 10 (520\%)* \\
\hline & & $\begin{array}{l}\text { BTA (+): } 0 \\
\text { BTA (-): } 10\end{array}$ & $10(0<, 0 \%)$ \\
\hline & LED & & $13(68,4 \%)^{*}$ \\
\hline & & $\begin{array}{l}\text { LED normal: } 3 \\
\text { LED tinggi: } 10\end{array}$ & \\
\hline & Mantoux test & & $4(21 \%)^{*}$ \\
\hline & & $\begin{array}{l}(+): 3 \\
(-): 1\end{array}$ & \\
\hline & Rontgen thorak PA & & $11(57,9 \%)^{*}$ \\
\hline & & $\begin{array}{l}\text { Kesan KP }(+): 9 \\
\text { Kesan KP(-): } 2\end{array}$ & \\
\hline \multirow[t]{2}{*}{6} & Tindakan & & \\
\hline & $\begin{array}{l}\text { Operatif } \\
\text { OAT }\end{array}$ & $\begin{array}{c}15(78,9 \%) \\
13(68,4 \%)\end{array}$ & \\
\hline
\end{tabular}

Ket: *) Jumlah pasien yang dilakukan pemeriksaan terkait.

Berdasarkan tabel 1, subyek pada penelitian ini berjenis kelamin laki-laki sebanyak 11 (57,90\%), dengan interval usia 9 - 60 tahun dengan median 26 tahun. Tuberculosis paru didapati 4 pasien dari 19 pasien. Dari (13/19) pasien yang menjalani pemeriksaan LED, (10/13) pasien mengalami peningkatan LED. Sebanyak 10/19 pasien diperiksa BTA dengan hasil BTA negatif pada 10/10 pasien. Letak gibus kebanyakan di lumbal (14/9) dan torakal (5/19). Keluhan neurologis paraparese inferior didapatkan (4/19) pasien, dan hemiparese pada (1/19) orang.

Analisa lebih lanjut pada 15 kasus menunjukkan data klinis bahwa pasien datang pada tahap akhir. Pada tahap akhir spondylitis TB, resiko komplikasi fatal iskemik vertebrae, meningkat. Pada kasus dimana TB belum terbukti melalui cara identifikasi lain (Thorak PA, BTA sputum, marker local/sistemik) laminektomi jugabermanfaa tsebagai diagnostik ${ }^{7}$.

\section{KESIMPULAN}

Kasus spondilitis TB di NTB kebanyakan berasal dari kabupaten Lombok Barat dan Lombok Tengah. Letak gybus didominasi area lumbal. Tuberculosis paru yang diduga sebagai sumber primer spondylitis TB tidak dominan pada penelitian ini.

\section{DAFTAR PUSTAKA}

1. De Vuyst D, Vanhoenacker F, Gielen J, Bernaerts A, De Schepper AM. Imaging features of musculoskeletal tuberculosis. European Radiology 2003;13 (8):1809-19 
2. Moon MS. Development in the management of tuberculosis of the spine. Curr Orthop. 2006;20:132-40

3. Mehta, J S. Bhojraj S Y.2001. Tuberculosis of The Thoracic Spine : A Classification Based On The Selection of Surgical Strategies. The Journal of Bone and Joint Surgery.vol. 83-b, no. 6, august 2001

4. Paramarta, I G E. Purniti, P S.Subanada, I B. Astawa. 2008. SpondilitisTuberkulosis. Pediatri 2008;10(3):177-83). (accessed: 29 Maret 2013)

5. Hidalgo A. 2012. Pott disease (tuberculous spondylitis). http:// emedicine.medscape.com/article/226 141-overview\#showall. (accessed: 29 Maret 2013)

6. Dikes Provinsi NTB 2012. Profil Kesehatan Provinsi NTB 2012.

7. V.P. Djientcheu, F.F. Mouafo Tambo, I.S. Ndougsa, N.J. Eloundou, I.N. KounaTsala, M. NgoweNgowe, O.G. Andze, M.A. Sosso. The role of surgery in the management of Pott's disease in Yaoundé: A review of 43 cases. Ortho \& Trauma: Surg\& ResearchVol 99 (4): 419-423, June 2013 available at: http://www. sciencedirect.com/science/article/pii/ S1877056813000765 